\title{
Scope for Applications Management in India of Soft Computing in effective Classroom
}

\author{
Subhasree Pal ${ }^{1}$, Dr. Parimal Sarkar ${ }^{2}$, Souren Bhattacharya ${ }^{3}$ \\ ${ }^{1}$ Research Scholar, Department of Education, NSOU, West Bengal, India \\ subhoriddhipal2010@gmail.com \\ ${ }^{2}$ Assistant Professor, School of Education, NSOU, West Bengal, India \\ srkprml@gmail.com \\ ${ }^{3}$ Research Scholar, Department of History, University of Technology, Jaipur, Rajasthan, India \\ sbhattacharya1977@gmail.com
}

Corresponding Author email: sbhattacharya1977@gmail.com

\begin{abstract}
The present paper throws light on how different unwanted situations and real-time problems in teaching-learning platforms, in-classroom ambience, prediction about students' performance and success, probability of their retention can be addressed effectively and efficiently to create a positive ambience for teaching as well as learning using soft computing in India. A classroom is a place where the bricks of the future foundation of any child are built. Therefore, a lot of things are closely associated with classroom management. Where the general age-old system fails to diagnose, Soft Computing emerges as the only way to detect, analyse and solve the problem with utmost excellence and adequacy. Soft Computing is a branch of science in which thinking, reasoning and ratiocination are been considered tools to address the real problems in the real classroom scenario. It is a package where machine learning, genetic algorithms, artificial neural network analysis, fuzzy logic etc. are used to bring out the utmost learning outcomes in a classroom. The atmosphere in which a student learns, the learning environment where the seed of knowledge is sowed, the teaching and behaviour of the teacher which is like nourishing sunshine that helps the process of synthesising knowledge are the backbones of any learning system. Soft computing has the potential to address the issues.
\end{abstract}

Keywords: Classroom Management, Machine Learning, Artificial Neural Network, Fuzzy Logic, Artificial Intelligence, Genetic Algorithm

\section{Introduction}

Effective classroom management denotes the effective and wisely usage of resources accessible in classroom scenarios to attain the consummate goal of the teaching-learning process. (Isuku, 2018) We live in the era of the Knowledge Revolution (Chitinlike, 1996) in which hard computing and Soft Computing (SC) domain the whole area of human knowledge with their immersive power of communication and problem-solving applications. The mechanism of the World economy is transformed itself into a 'resource-intensive to knowledgeintensive economy' (Beck, 1992). Knowledge is one type of input process which one can transform to others keeping everything intact and as before. One of the best institutions which play this purpose effectively and efficiently is a classroom. The architecture of a student's life is portrayed in the classroom, how efficient a classroom maybe, to that extent a student enriches. But the age-old problem in this region is to
Diagnosis how a student can take part in teaching-learning sessions competently and to anchor the knowledge intact and for a long time to use, reuse and synthesis (Garcia et al., 2007). The answer to this question lies in technology which facilitates the communications and interactions between the knowledge giver and the receiver even in the time of pandemic and has gifted the boon to improve these communications and interactions even more (Ali, 2013). Along with that, it is also the priority of the education system is to improve the comprehension, understanding and application level of students to deal with problems in real-life scenarios adequately and fruitfully, to handle competently with emblem and motif and has inbuilt himself the ability to make wise decisions as per situation demands (Viswanathan ,2020). It is therefore not exaggerated to vindicate that soft computing facilitates education to a next greater level with fine-tuning with other necessary components 
(Chen et all. 2015). Development of different soft computing and implementation of them in the education system can be added an extra flavour to serve this dish with excellence in front of the World community (Hwang et al., 2004). Even soft computing extends its helping to make the environment more inclusive and productive for those students with special needs (Bhattacharya \& Pal, 2021).

\section{Different elements of Soft Computing encompass:}

- Fuzzy Logic: Fuzzy logic is an application of using natural language which does not contain only 0 and 1 rather has multi-valued logic which contains and work with approximate reasoning irrespective of the fixed value system that binary has (Walch,2021).

- Evolutionary Computing: It is a periphery of Artificial Intelligence that is used for problem-solving purposes. It contains algorithms to make an understandable optimization inspired by the evolution process (Weerakoon \& McMurray, 2020).

- Machine Learning: It is the branch of SC where computer algorithms are used to get a solution of a problem that in nature is uncertain, approximation and inaccurate (Machine Learning What It Is and Why It Matters, n.d.).

- Probabilistic Reasoning: It uses probability and logic together to respond to the unknown and uncertain situation in which now is (Deshmukh \& Gupta, 2014).

- Further Artificial Intelligence, Genetic Algorithm, Artificial Neural Network, Data Mining are essential elements of it.

Again, there is a prime need to beat the limitations of Web2.0 and build up the facilities to use Web3.0, Semantic Web before implementing soft computing in the teaching-learning scenario. It assists teachers in evolving tutoring system for any course which helps to arrange the curriculum as per chapter, contents, sub-chapters etc. 'Making Content Machine-Understandable' is the main concern of semantic web who serves the documents within a wink of the eye. Semantic web inspires 3D shape irrespective of 2D which helps to gain knowledge about anything more accurately and precisely. It provides the desired scope to modify the curriculum with the need and priority of the existing system and society. Furthermore, it enhances the opportunity to adopt collaborative approaches among different institutions which overcome the shortage of teachers and elaborate the scope of sharing knowledge and experiences. In the blended learning approach or online teaching-learning scenarios, u-learning only can be provided through the semantic web which enables the teacher to control classroom scenarios from anywhere and at any time.

The present article explores the scope for using soft computing as effective classroom management. Further, the article throws light to analyse and evaluate the positive outcome of application soft computing in classroom situations on retention, dropouts and learning outcomes in the Indian context and to assess the efficacy of applying soft computing to combat the loopholes of the classroom teaching-learning process.

\section{Methodology:}

The paper follows the qualitative descriptive method to analyse this study based on secondary data. An extensive literature review has been done in this regard. Data is collected from different journals, research papers, government records, newspapers on education, students' orientation, classroom problems, application of Artificial intelligence, fuzzy logic etc

\section{Classical Classroom Management in Indian Scenario:}

The basic intentions that work behind in every classroom management are to create such an ambience which in builds appropriate behaviours among children and enhance the level of engrossment in studies, aptitudes which ultimately boosts up the ratio of academic engagement (Kratochwill, 2010). Classroom management is not only emphasising action to create a stimulating learning ambience but also emphasize on to touch the goal. A positive classroom breeds a socio-emotional learning environment in where the motto of 'learning to live together' get its real touch. If the classroom can be visualised from the side of students, it certainly set up the expectations of behavioural and academic communication along with the stress on the creation of cooperative learning ambience ("Delors Commission," 1996). A large variance of students gets entered into a single classroom with different demands and variance needs. For a single teacher, it is impossible to meet the different needs and aspirations of the learners within the stipulated time of the classroom. Again, norms are made to include special children in normal school to add them as a member of a miniature society i.e., school through inclusive education. In large gatherings of a classroom, it is quite impossible to satisfy and quench the thirst of those special students. Due to different reasons in a classroom scenario, there is a dilapidated picture of the Indian classroom scenario that has come forefront. Where in primary, the ratio of gross enrolment is 93.32 in the seventh survey, the same ratio has approximately remained half when they are upgraded to the upper primary stage that is 58.42. (National Council of Educational Research and Training, 2009). As per Unified District Information System for Education (UDISE) report in 2019-20, it is revealed that there is a $16.07 \%$ dropout rate in the second section that can be visualised in UDISE Dash Board is in itself shocking and heartbreaking (UDISE+2019_20_Booklet.Pdf, 2020). As per the Annual Status of Education Report (ASER) in 2019 done by NGO Pratham revealed that in the first standard more than $40 \%$ of students could not recognise the alphabets and only $41 \%$ could able to identify the two digits arithmetic numbers if the superstructure of any building is so weak then how can we ever dream to make multi-storied buildings upon it (Wadhwa,2020). As previous, no university is able to make their position in World Ranking as per ARWC among Top 20 as well as Top 400. The first secured ranking is made by the Indian Institute of Science which is between 401-500 and then the University of Calcutta by securing the place in 601-700. (INDIA TV Education Desk, 2021). If a classroom is not strong enough in its ambience, then the outcome product itself is weak enough to flag its excellence. This evidence seen is in the case of synthesis of knowledge that IP filling activity by India. Being the second large country after China, having a larger education system India has just filed 2,053 patents application which consists only a 
fewer portion larger than $1 \%$ and in industrial ground India is only able to file only 3 in count along with only $0.07 \%$ filing for trademarks in 2019 (Pattanayak, 2020). Those are not the demerits of students because every student has some special inclination and aspirations, it is the Indian classroom that fails to support its students when they need, it fails to realise the potentiality of the student which is in badly need to be facilitated by the end of classroom management. In 2019, the government of India has made an ambitious plan to transform the learning outcome with full industry orientation and more specific employability skills (MHRD, 2019). A poor learning environment breeds out poor categories of students who fail to combat the outer world outside of the classroom with the same grandeur and spirits. To improve the scenario, the teacher badly needs a helping hand to make the management of the classroom more fruitful. Soft Computing is that application that helps in this area to uplift the standard of classroom management to bring out desired learning outcomes. Because the loopholes in classroom management lies the detection of students' strength, assessing their classroom performances, getting ideas about their aptitudes, to get predictions about students, to realize the real cause of retention etc. Soft Computing turns out as an effective to locate all those peripheries of students with appropriate diagnosis

\section{Application of different elements of Soft Computing in Classroom management: Fuzzy Logic:}

This soft computing helps to evaluate students in a classroom scenario in a very effective way. In teaching-learning session, a teacher has to access the aptitude and knowledge to bring out the learning outcomes of students. The design of our society is as such, the assessment reports of students determine the entry of a course along with eligibility for entry into a job. So, it is the prime duty of an education system to access the assessment minutely and precisely for the benefit of the students. As per the standard classical model of assessment, a gradation system expressed either in numerical or alphabetical values denotes and expresses a student's learning outcomes. But here lies the question is this grade itself enough to precisely vindicate the performance and aptitude level of a particular student? Not only that, the teacher is himself doubtful about this numerical expression of performance. Here lies the success of Fuzzy Logic. Applying multiple values widens the scope to evaluate students more perfectly (Yadav et al., 2014). It also helps in determining teacher's efficiency. Again, a new developed Fuzzy Logic has been introduced to differentiate between a higher IQ student with lower IQ ones. Its prime purpose is to develop the learning as per the student's need and necessity. It consciously keeps an eye on students' growth and performance and modulates and plans the next phase as per needs comparing the present one with the previous (Yadav \& Singh, 2011). Fuzzy logic can be also used to appraise a teacher more minutely than the present one. Fuzzy time series is applied to augur and presage the probability enrolment of students in higher education (Singh, 2017).

Machine learning and teaching-learning process:

though Machine learning is an integral part of artificial intelligence (AI) its work differs from AI. Machine Learning (ML) is the ability of the computer to learn from statistical input without any explicit programme (Samuel,1959). This characteristic of ML can be tactfully used in classroom management. Machine Learning has the potential to predict the performance of the students, test and grade the students, improve retention and support the educators (Kucak et al., 2018). In the countries like India where the pupil-teacher ratio (PTR) is below the prescribed standard and the dropout rate is high; there it can play a decisive role. The ML can scrupulously dive into the data, make connections and analyse data thus enabling the educators to analyse precision teaching-learning outcomes with minimum human effort. It can also help the teachers in doing nonacademic works like scheduling, preparing tasks etc. As the burden of non-academic works are reduced so the educators can engage themselves more in academic activities. Another problem often encountered by the teachers is the conduction of tests and gradation. ML as a part of Artificial Intelligence may effectively be used for testing and gradation without human error and human biases. ML can play the role of predictive analytics where by analysing the cumulative data of the students at the of the session it can predict probable dropout or students at the risk of failure (Wu et al.,2018). In India, the dropout rate and failure rate at examinations specially in higher education is high enough due to several socio-economic reasons. Several studies have been conducted to find the probable reasons behind dropout. The predictive analytical ability of ML may be very useful for the retention of students. Moreover, with learning analytics, the teachers can assess the learning outcome and also precisely detect the weakness of the individual by this process of hyperpersonalisation. The language barrier is another hindrance for the students for assimilation of the subjects they study. With the application of Natural Language Processing (NLP), ML can promote language learning in natural settings and enhance the learning outcome (Khaled, 2014).

\section{Artificial Neural Networks (ANN):}

Artificial Neural Networks (ANN) is a computational mathematical model which functions in similarity with the human brain or as the cognitive learning process in natural neural networks. Like the neurons of the human brain work which work individually and interact with the neurons, in the same manner, the ANN can process raw data and transform it into valuable data which facilitates the teaching-learning process. As a part of the Machine Learning algorithm, it shows the mistakes made by ML. Taking it as probability, humans are taught not to do mistakes in that particular area. Moreover, by manipulating data about students' previous academic performance, socioeconomic conditions and high school behaviour it is possible to predict their success or failure in a particular subject in higher studies (Carlos et al., 2021). Studies have revealed that Even with the application of ANN it is possible to estimate the electricity budget for an educational institution (Kwangbok et al., 2014). Several Indian higher education institutions are now offering online courses. students face difficulties while selecting a particular which may be best suited for them. Here application of ANN can predict the number of possible student enrolments (Kardan et al.,2013).

\section{Genetic algorithm}

A genetic algorithm is a computation method of mimicking the natural evolution and selection process (Lakshmi,2013). Studies on genetic algorithms have confirmed that it has the predictive 
ability of enrolment of students in a specific course and suitable category of students for it, detection of probable fraudulent activities of the students and student retention (Kalles,2006; Kusack et al., 2019). It can also make class routine, schedule and conduct automated exams. In this new digital era, the Indian schools and higher education institutions suit most to use genetic algorithm method to impart quality education. In India, as elearning is gaining popularity day by day so the adoption of genetic algorithms can effectively monitor students' performance, conduction of automated assessment tests, recommend courses for the students and improve student retention rate thus leading to quality education.

\section{Bayesian Network}

A classroom is the humming centre of different birds. They have their very own style to represent themselves, different ways to respond towards teaching-learning sessions and they individually have their very unique way to bag the lecture. In general classroom management, it is a very difficult as well as an impossible task for a teacher to distinguish each student's behaviour towards learning. The Bayesian Network makes it easy for teachers to differentiate different learning styles of the students with more precision and accuracy (Garcia et al., 2007). Again, it diagnoses the mistakes that are done on the part of examiners in the time of assessment the paper of students so that the mistake can't be happened in future and suggest the way to avoid it. (Xenos, 2004)

\section{K-means Clustering}

Achieving quality in education is one of the prime concerns of educational management. The quality of students reflects the quality of the institute where they carry on their studies. Again, students' performance reflects their inclinations as well as academic career. Indian educational institutions lack quality. Imparting quality education is the prime concern of the authorities and for achieving that introduction of Total Quality Management is the need of the hour (Bhattacharya \& Pal,2020). Clustering is used to separate a large data set according to its similarities to different clusters. K-means clustering is applied to bring out the academic performance of students in respect of their career and then they are compared in respect with the local result to establish the difference. In a nutshell

\section{Data mining:}

Extracting meaningful information from the large raw database is known as data mining (Algarni, 2016). It is an essential part of ML in the framework of soft computing. Data mining is used for knowledge discoveries. It relieves the human brain from overloading data. In a large database, it is quite difficult to establish any complex relationship between them. Data mining can extract any hidden unique relation from a large data which can be used through ML in soft computation for reducing imprecision and uncertainty. Thus, it can work as knowledge discoveries in data from a large database. In India, U-DISE database contains all essential information about school students. Through data mining we can get valuable information like their performance, the possibility of success in the higher class, their learning progress, learning outcome, behaviour and weakness in the soft computation framework. In higher studies also data mining can give us an idea about students' performance, their retention rate and also select courses (Goyal \& Vohra, 2012).

Artificial Intelligence:
The world civilization has entered the age of big data. At present, scientists are engaged in exploring the potential capabilities of Artificial Intelligence (AI) for use in the field of education. Like the human brain the AI can process complex data, can learn, adapt and synthesize (Popenici\&Ker,2017; Huang et al, 2021). In the Global Education 2030 agenda, UNESCO has set the goal to, "ensure inclusive and equitable, quality education and promote lifelong learning opportunities for all" (Leading SDG 4 - Education 2030, 2019) for the attainment of sustainable development. Though slowly, India is already entered the field of digital literacy. Special emphasis is given to online learning in the drafted National Education Policy,2019. for the attainment of inclusion and quality in higher education, the 'NITI Aayog' in 2018 has drafted a five-year plan namely 'Education Quality Upgradation and Inclusion Programme' (EQUIP) with extensive use of AI. Further, it proposed a 70-point measurement scale to assess the learning outcome of the students with the use of AI (Roy,2021). There is a huge scope for using AI in the Indian educational arena. There are only 2.4 teachers per 1000 students and the gross enrolment ratio (GER) is only $26.4 \%$ in higher education. Students from the remotest areas and students with special needs are the worst sufferer in all levels of education. AIpowered 'teacherbot' can be used to solve problems effectively. AI can be used in collaborative learning for an asynchronous group of students. it is possible to arrange argument, debate and discussion on a topic for multiple groups of students at a time (Mclaren et al.,2010). The monitoring learning process, providing personalised guidance and checking progress is possible with application AI. while mainstreaming students with disabilities, AI power hearing aid, visual augmentation device, speech detector and 'Phonological Awareness Educational Software'(PHAES) can be used effectively to get desired learning outcome (Drigas et al., 2012; Drigas\& Ioannidou, 2013, Garg, 2020).

\section{Proposed Plan for Upgrading School Infrastructure for Soft Computing:}

If a school does not have adequate infrastructure to adopt soft computing and semantic learning environment into its periphery, all inventions go to waste in another sense. Digital semantic learning infrastructure can transform monotonous learning into joyful learning providing a conductive learning ambience to metamorphosis humans into human resources. Unlike the blackboard and chalk-duster approach, it provides teachinglearning in more effective and attractive way at anywhere and at any time. Following basic types of equipment are the basic need to transform the traditional classroom into a semantic ULearning classroom with soft computing approaches. The first and foremost criteria in this aspect are to make arrangements for a high-speed uninterrupted internet connection. Along with those following things are needed to make the competent atmosphere in classroom scenario:

- Introducing of Multimedia Centre for the constant support, implementation of new opportunities related to ICT archetype.

- Every classroom must have Interactive whiteboard along with a projector and computer. 
- The classroom has to be equipped with LED/ LCD panels for using 3D animations, graphics to provide students real-world scenario

- Digital Podium certainly adds more flavour to it.

- Digital library facilities should be provided to the students to celebrate the legacy of the semantic web and U- Learning.

- E-diary on the online portal of the school should be introduced to inform parents about their wards' performances and school activities

- E-games can assist students to enhance the capability of critical thinking and learning capabilities

- Soft computing should be assembled with classroom management process and evaluation of them should be done through with help of these soft wares. Students also can submit their assignments and projects through it.

- School campus has to be upgraded to Wi-Fi campus for availing those facilities

- Cloud-based E-learning ambience should be initiated for sharing of data and multi-tasking user collaborations.

- A biometric attendance system for all should be implemented

\section{Teachers' orientation:}

Apart from infrastructural facilities, another important aspect is teachers' orientation in this regard. In the School education sector, the progress of using ICT is beyond satisfactory level. Teachers' competency in using the web and its components should be encouraged and several workshops and practical seminars have to be organised for increasing their competency in using these profoundly. Further in the Indian higher education sector, though the use of ICT and AI is significantly increasing specially for the STEM subjects, engineering and technology; and medical sciences but has very limited use in other branches of study. Regular training on ICT and the use of soft computing for the teachers is the need of the hour for making the teachinglearning process more effective and for desired learning outcome.

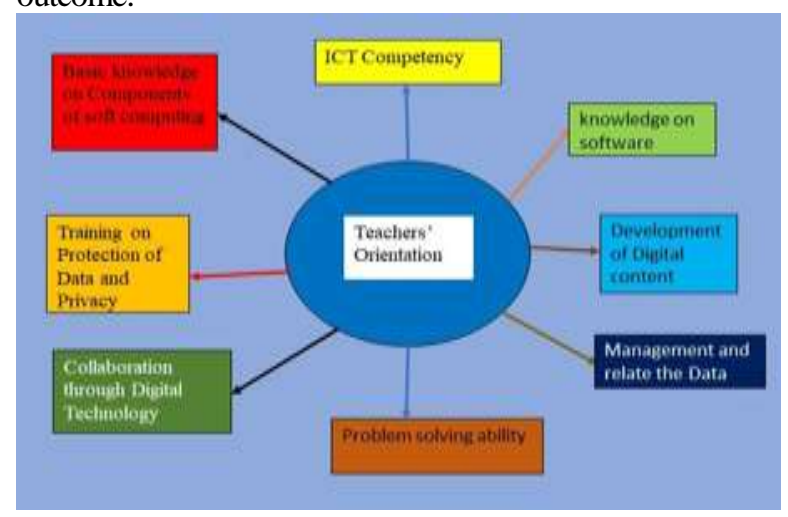

\section{Framework for Implementation in Classroom Scenario:}

We now have different learning support facilities such as ubiquitous networks, semantic web, soft computing applications, and wireless communication. The question of this hour is that how we can accumulate all these components together to breed a better teaching-learning environment to cope up with rapid technological as well as societal transformations.

Every student is different from each other as well as their learning patterns. Multi-tutoring allows us customized learning materials and the teacher takes the initiative to provide the customised learning materials based on students' previous performance which can be obtained through Data-Mining. Again, before making customised learning materials, we need to get a preview about the learning styles and patterns of that specific student which can be done through using Bayesian Network and previous knowledge about a subject which can be obtained through using Fuzzy Logic. U-learning provides context-aware learning support at any time and at anywhere with a real classroom approach. Artificial Neural Network and Machine Learning assist to create data on students' performance and Data Mining supplies all the information at any time when it is needed. Again, the Genetic Algorithm provides classroom planning regarding classroom routine, schedules and also conducts automated examinations to help teachers. Further, Fuzzy logic helps to evaluate students more precisely and perfectly and Machine Learning helps to improve the scenario of retention in a classroom scenario and helps educators to evaluate and grade students' performance. In addition to that, K-means Clustering helps the student to realise institution quality before entering the teaching-learning scenario. Artificial Neural Network also helps the institution to realise the depth and understanding of students about a particular subject and allow the institution to give entry of student in this subject or not.

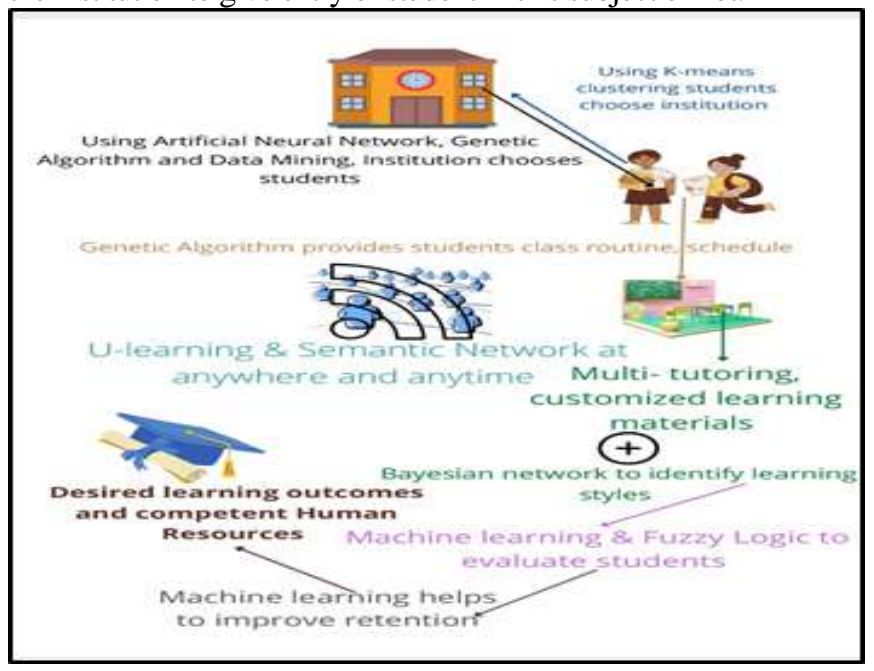

Figure 2: Framework for implementation of soft computing Source Author

Figure 1: Teachers' orientation strategy

Source: Author 


\section{Impediments in Implementations:}

- India perhaps prepares itself to adopt Soft Computing in the education system for better learning outcomes in near future. But till now there is no application of Soft Computing up to the Higher Secondary level which is the platform that makes the route to the paradigm of Higher Education. In Higher Education 'Swayam' platform is made to provide ample scope for establishing their excellence in the higher study ( SWYAM, 2016) but still, there is a lot to implement and include.

- There is no route map still adopted to implement Soft Computing from primary level to Higher Education to evaluate students' academic performance more precisely and appropriately. Government should have a focus on that part for the betterment of society as they are the future tax-payer of society.

- From primary school to university are badly struggling for the lack of funds. Soft Computing needs wellestablished internet services and a lot of funds to run the programme successfully but without the fund allocation on the part of the Government, it is quite impossible for educational organisations to set up and maintain the infrastructures.

- The allocation of using a budget for research only contains $0.6 \%$ of the total budget in 2019 (Bhattacharya \& Pal, 2020) which is itself a large hurdle to implementing Soft Computing in the education sector. Soft Computing needs a lot of researchers who works behind it with a motive to implement it at low cost and low maintenance. For training sessions of Professionals, recruitments of Soft Computing professionals, there is in need a lot of funds. To reduce the quality gap between the students abroad and Indian, Soft Computing has to be introduced and for this purpose, Government has to raise the amount of budget allocation in the research field.

- Soft Computing needs a lot of data to bring out the perfect scenario of the picture. Different sectors have to work collectively and amalgamate ways to collect data. Government should pay attention in this regard.

- Educators and teachers need comprehensive training on soft computing.

\section{Conclusion}

Education means the all-round development of students. We live in the era of competition and rat race where everyone tries to run first to show their excellence. The achievement of students ensures the stability and supremacy of an educational institution. Within a short period and not doing so much labour, Soft Computing certainly does a great favour to assess students more perfectly and precisely. The classification of students done by Soft Computing into different categories will provide teachers with great help to design and deliver the lessons as per the categories of students. But there is no application of Soft Computing to get an analysis of different teaching methodologies for different subjects. Evaluation system can be improved by using Soft Computing and if delivering technique of lesson can also be assessed with Soft Computing, the whole scenario of classroom management has going to be changed. It is turned into a more fruitful and productive place to be got enlightened. India being the fastest growing economy and home of the largest youth population, soft computing could be instrumental in addressing classroom issues more effectively and learning outcomes will be at par with global needs.

\section{References}

[1] Ali, S. (2013). Challenges and Benefits of Implementing Tablets in Classroom for e-Learning in a K-12 Education Environment _ Case Study of a School in United Arab Emirates. researchgate.net/publication/251231739_Challenges _and_Benefits_of_Implementing_Tablets_in_Classro om_for_e-Learning_in_a_K-

12_Education_Environment__Case_Study_of_a_School_in_United_Arab_Emirat es

[2] Algarni, A. (2016). Data Mining in Education. International Journal of Advanced Computer Science and Applications, 7. 10.14569/IJACSA.2016.070659.

[3] Bhattacharya, S. \&, \& Pal, S. (2021). SCHEDULED TRIBE GIRL STUDENTS WITH SPECIAL NEED AND ARTIFICIAL INTELLIGENCE. European Scholar Journal, 2(6), 195-201. https://scholarzest.com/index.php/esj/article/view/10 $14 / 860$

[4] Bhattacharya, S. \&, \& Pal, S. (2020). Leveraging Indian Higher Education to Global Standard through Total Quality Management. Tathapi, 48, 152-164. https://www.academia.edu/51133726/Leveraging_In dian_Higher_Education_to_Global_Standard_throug h_Total_Quality_Management

[5] Chen, J.-F., Hsieh, H.-N., \& Do, Q. H. (2015). Evaluating teaching performance based on fuzzy AHP and comprehensive evaluation approach. Applied Soft Computing, 28, 100-108. https://doi.org/https://doi.org/10.1016/j.asoc.2014.11. 050

[6] Carlos, F., Rodríguez,H., Mariel, Mu., Eva, K., Eduardo, C. Artificial neural networks in academic performance prediction: Systematic implementation and predictor evaluation. Computers and Education: Artificial Intelligence, 2, https://doi.org/10.1016/j.caeai.2021.100018.

[7] Delors Commission. (1996). In wikipedia. https://en.wikipedia.org/wiki/Delors_Commission

[8] Deshmukh, A. R., \& Gupta, P. S. R. (2014). Data Mining Based Soft Computing Methods for Web Intelligence. International Journal of Application or Innovation in Engineering \& Management (IJAIEM), 3(3), 376-382

[9] Drigas, A., \& Ioannidou, R.-E. (2012). Artificial intelligence in special education: A decade review. International Journal of Engineering Education. https://www.researchgate.net/publication/249656322 
_Artificial_intelligence_in_special_education_A_dec ade_review

[10] Huang, J., Saleh, S., \& Liu, Y. (2021). A review on artificial intelligence in education. Academic Journal of Interdisciplinary Studies, 10(3), 206-217. https://doi.org/10.36941/AJIS-2021-0077

[11] Garg, S. (2020). Impact of Artificial Intelligence in Special Need Education to Promote Inclusive Pedagogy. International Journal of Information and Education Technology, 10. https://doi.org/10.18178/ijiet.2020.10.7.1418

[12] García, P., Amandi, A., Schiaffino, S. N., \& Campo, M. R. (2007). Evaluating Bayesian networks' precision for detecting students' learning styles. Comput. Educ., 49, 794-808.

[13] Goyal, M., \& Vohra, R. (2012). Applications of Data Mining in Higher Education. International Journal of Computer Science Issues, 9.

[14] Hwang, G., Huang, T. C.-K., \& Tseng, J. C. R (2004). A group-decision approach for evaluating educational web sites. Comput. Educ., 42, 65-86. https://doi.org/10.1016/S0360-1315(03)00065-4

[15] India TV Education Desk. (2021). ARWU Shanghai Ranking 2021: List of top 10 Universities in India. INDIA

TV.

https://www.indiatvnews.com/education/news-arwuranking-shanghai-ranking-top-10-universities-ofindia-top-10-indian-universities-arwu-ranking-2021jnu-iisc-calcutta-university-aiims-727355

[16] Isuku, E. J. (2020). Classroom Management and Problems Associated With It. In Olusegun Kolawole and Bashiru Lawal (Eds) A Handbook of Teaching Practice, June. https://www.researchgate.net/profile/Eragbai_Isuku/ publication/342183928_Classroom_Management_an d_Problems_Associated_with_it/links/5ee7e44a299b f1faac56ac4e/Classroom-Management-and-

Problems-Associated-with-it.pdf

[17] Kalles, D., \& Pierrakeas, C. (2006). Analyzing student performance in distance learning with genetic algorithms and decision trees. In Applied Artificial Intelligence (Vol. 20, Issue 8). https://doi.org/10.1080/08839510600844946

[18] Kardan, A. A., Sadeghi, H., Ghidary, S. S., \& Sani, M. R. F. (2013). Prediction of student course selection in online higher education institutes using neural network. Computers \& Education, 65, 1-11. https://doi.org/https://doi.org/10.1016/j.compedu.201 3.01 .015

[19] Khaled, D. (2014). Natural Language Processing and its Use in Education. International Journal of Advanced Computer Science and Applications, $5(12)$, 72-76. https://doi.org/10.14569/ijacsa.2014.051210

[20] Kratochwill, T. (2010, February 16). Classroom management module. American Psychological Association. http://www.apa.org/educationcareer/k12/modules-classroom-management
[21] Kučak, D., Juričić, V., \& Đambić, G. (2018). Machine learning in education - A survey of current research trends. Annals of DAAAM and Proceedings of the International DAAAM Symposium, 29(1), 0406-0410.

https://doi.org/10.2507/29th.daaam.proceedings.059

[22] Kučak, D., Juričić, V., \& Đambić, G. (2019). Application of genetic algorithms in higher education area. Annals of DAAAM and Proceedings of the International DAAAM Symposium, 30(1), 343-347. https://doi.org/10.2507/30th.daaam.proceedings.045

[23] Lakshmi, T. M., Martin, A., \& Venkatesan, V. P. (2013). An Analysis of Students Performance Using Genetic Algorithm. Journal of Computer Sciences and Applications, 1(4), 75-79. https://doi.org/10.12691/jcsa-1-4-3

[24] Leading SDG 4 - Education 2030. (2019). UNESCO. https://en.unesco.org/themes/education2030-sdg4

[25] Machine Learning What it is and why it matters. (n.d.). SAS. Retrieved September 10, 2021, from https://www.sas.com/en_in/insights/analytics/machin e-learning.html

[26] Mclaren, B. M., Scheuer, O., \& Mikšátko, J. (2010). Supporting Collaborative Learning and EDiscussions Using Artificial Intelligence Techniques. International Journal of Artificial Intelligence in Education, 20, 1-46. https://doi.org/10.3233/JAI2010-0001

[27] MHRD. (2019). National education policy. Ministry of Education Government of India, 1-71. https://www.education.gov.in/sites/upload_files/mhr d/files/Draft_NEP_2019_EN_Revised.pdf

[28] National Council of Educational Research and Training. (2009). All India School Education Survey. https://ncert.nic.in/pdf/programmes/AISES/8th_AIS ES_Concise_Report.pdf

[29] Oyelade, O. J., Oladipupo, O. O., \& Obagbuwa, I. C. (2010). Application of k Means Clustering algorithm for prediction of Students Academic Performance. CoRR, abs/1002.2425. http://arxiv.org/abs/1002.2425

[30] Pattanayak, B. (2020, August 24). Global patents applications: India puts up a poor show, even Huawei has more filings. Financial Express. https://www.financialexpress.com/industry/globalpatent-filings-huawei-alone-has-more-claims-thanindias-dismal-share-at-below-1/2063285/

[31] Popenici, S. A. D., \& Kerr, S. (2017). Exploring the impact of artificial intelligence on teaching and learning in higher education. Research and Practice in Technology Enhanced Learning, 12(1), 22. https://doi.org/10.1186/s41039-017-0062-8

[32] Roy, A. (2021). Responsible Ai \# Aiforall. Niti Aayog, February, https://www.niti.gov.in/sites/default/files/202102/Responsible-AI-22022021.pdf

[33] Samuel, A. L. (1959). Some Studies in Machine Learning Using the Game of Checkers. IBM Journal 
of Research and Development, 3(3), 210-229. https://doi.org/10.1147/rd.33.0210

[34] Singh, P. (2017). A brief review of modeling approaches based on fuzzy time series. International Journal of Machine Learning and Cybernetics, 8(2), 397-420. https://doi.org/10.1007/s13042-015-0332-y

[35] SWYAM. (2016). Government of India. https://swayam.gov.in/about

[36] UDISE+2019_20_Booklet.pdf. (2020). Ministry of Education, $\quad$ GOI. https://dashboard.udiseplus.gov.in/\#/home

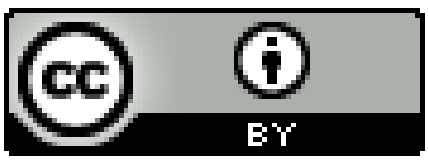

[37] UNESCO. (2019). Artificial Intelligence in Education: Challenges and Opportunities for Sustainable Development. https://en.unesco.org/news/challenges-andopportunities-artificial-intelligence-education

[38] Viswanathan, R., \& Rathna, R. (2020). An approach on soft computing technique-based student learning system. Journal of Critical Reviews, 7(9), 357-366. https://doi.org/10.31838/jcr.07.09.76

[39] Wadhwa, W. (2020, January 15). Chalk and cheese in private vs. government schools. The Hindu. https://www.thehindu.com/opinion/op-ed/chalk-andcheese-in-private-vs-governmentschools/article30569656.ece

[40] Walch, K. (2021). How neural network training methods are modeled after the human brain. https://searchenterpriseai.techtarget.com/feature/How -neural-network-training-methods-are-modeled-afterthe-human-brain

[41] Weerakoon, C \& McMurray, A. (2020). Theoretical and Practical Approaches to Social Innovation. IGI Global. https://doi.org/10.4018/978-1-7998-4588-1

[42] Wu, J.-Y., Hsiao, Y.-C., \& Nian, M.-W. (2020). Using supervised machine learning on large-scale online forums to classify course-related Facebook messages in predicting learning achievement within the personal learning environment. Interactive Learning Environments, 28(1), 65-80. https://doi.org/10.1080/10494820.2018.1515085

[43] Xenos, M. (2004). Prediction and assessment of student behaviour in open and distance education in computers using Bayesian networks. Computers and Education, 43(4), 345-359. https://doi.org/10.1016/j.compedu.2003.09.005

[44] Yadav, R. S., \& Singh, V. P. (2011). Modeling Academic Performance Evaluation Using Soft Computing Techniques: A Fuzzy Logic Approach.

[45] Yadav, R. S., Soni, A. K., \& Pal, S. (2014). A study of academic performance evaluation using Fuzzy Logic techniques. 2014 International Conference on Computing for Sustainable Global Development (INDIACom), 48-53. https://doi.org/ 10.1109/IndiaCom.2014.6828010 